\title{
THE CLINICAL USE OF NUCLEAR MAGNETIC RESONANCE SPECTROSCOPY FOR STUDYING HUMAN MUSCLE METABOLISM
}

\section{E. B. Cady}

Department of Medicine, Rayne Institute University College London School of Medicine R. D. Griffiths

Department of Medicine, Rayne Institute University College London School of Medicine R. H. T. Edwards

Department of Medicine, Rayne Institute University College London School of Medicine

\section{INTRODUCTION}

Nuclear magnetic resonance (NMR) imaging has recently become an accepted technique in the medical practitioner's armory (38). NMR spectroscopy (44) is a subtly different application of the same physical principles underlying NMR imaging, but the clinical potential for this modality is currently still under evaluation. The most important application of clinical NMR spectroscopy is for the nonin-

The research at University College London School of Medicine (UCLSM) is supported by the Wellcome Trust, Action Research, the Special Trustees of University College Hospital, and the Muscular Dystrophy Group of Great Britain. The studies have been carried out with the assistance of Dr. P. S. Tofts, Mr. D. Delpy and Mr. A. Chu of the Department of Medical Physics (UCLSM), and Mr. N. Taylor of Kings College London. The advice and assistance of Prof. D. R. Wilkie, FRS, is gratefully acknowledged. 
vasive monitoring of changes in metabolite levels and intracellular $\mathrm{pH}$ of intact tissues during physiological stress or in response to pharmacological agents or disease. The ${ }^{31}$ phosphorus $\left({ }^{31} \mathrm{P}\right)$ nucleus has been the most commonly investigated in muscle disease (39) but the applications of proton $\left({ }^{1} \mathrm{H}\right),(4,5,8)$ and ${ }^{13}$ carbon $\left({ }^{13} \mathrm{C}\right),(2,7)$ are currently being explored.

The main difference between NMR imaging and NMR spectroscopy is that in the former, protons (mainly in water) are positionally labeled by the application of magnetic field gradients so that the resonant frequency depends on the location of the ${ }^{1} \mathrm{H}$ nucleus in the tissue. By the use of suitable combinations of field gradients, a three-dimensional proton distribution can be derived which can give an image in any selected plane. In NMR spectroscopy, a highly homogeneous, static magnetic field is applied to the sample. This enables the nuclei in different chemical species to resonate at resolvable frequencies and so produce a spectrum. The separation of signals from various chemical species is made possible by the fact that each nucleus experiences a total magnetic field consisting of the main field plus a local field depending on chemical structure, and hence the resonances are chemicaly shifted and separated in the frequency spectrum.

The information acquired from NMR spectra consists of determinations of relative metabolite concentrations from measurements of resonance line areas and estimates of the intracellular $\mathrm{pH}$ from the chemical shifts of inorganic phosphate $(\mathrm{Pi}),(36)$ or the $\mathrm{C} 4-\mathrm{H}, \mathrm{C} 2-\mathrm{H}$, and $\mathrm{N}-\mathrm{H}$ protons of carnosine (5).

The NMR method has some advantages over needle or open biopsy procedures. Being noninvasive, harmless (42), and painless, NMR spectra can be collected as frequently as the signal-to-noise ratio will allow, and the procedure is acceptable to young children. The metabolites are assayed in situ, and it is believed that realistic estimates are obtained (47), whereas using the needle biopsy procedure, even the most skilful operator takes a few seconds to obtain and freeze the sample, allowing time for metabolite levels to change. Using NMR, typically 10 to $50 \mathrm{~cm}^{3}$ of tissue are examined, and the metabolite and $\mathrm{pH}$ results are more representative of overall muscle pathology, whereas the fact that needle biopsy gives only a small sample can be a problem in inhomogeneous tissue. Histological information, however, is not obtained, and hence NMR spectroscopy augments but does not replace the biochemical and histological uses of biopsy and other techniques.

\section{METHODS}

There are some problems associated with the clinical use of NMR spectroscopy. Practicalities concerning patient comfort while locating the muscle of interest in the center of the magnet bore have to be dealt with (15). The limb has to be adequately supported so that minimal pressure is applied to major blood vessels or nerves, and it is essential that some method of limb restraint is available to restrict movement. Studies of forearm muscle are usually made with the subject sitting on a chair; investigations of the calf muscles require the provision of a couch. The limb is usually grounded to reduce radio frequency $(\mathrm{Rf})$ interference. Usually one or two flexible, electrically conducting straps coated with contact gel are used to ground the limb; however, an alternative approach is to completely enclose the subject in a Faraday shield. 
In order to pick up the NMR signal, it has been found most practical to use a surface coil antenna consisting of one or more loops of wire placed on the skin adjacent to the tissue of interest (1). The surface coil is used for pulse transmission to perturb the nuclei as well as for reception of the subsequent free induction decay (FID). Insulation between the patient and the coil is usually provided by a thin (approximately $1 \mathrm{~mm}$ ) sheet of polytetrafluoroethylene (PTFE). Coils are tuned to the Rf for the particular nucleus and matched to the appropriate impedance while the limb is in position. The addition of a simple circuit allows the same coil to be "double tuned" for ' $\mathrm{H}$, and this allows the homogeneity of the main field to be optimized (shimmed) using the strong $\mathrm{H}_{2} \mathrm{O}$ signal. Both these tasks can be accomplished usually within 5 minutes. Parameters such as coil size and tuning (15), pulse length (related to flip angle), and pulse interval also need to be optimized to get maximum signal per unit time $(23,31)$. For short pulse intervals, correction factors have to be determined for each metabolite to allow for insufficient relaxation of the spin system between pulses. These factors can be estimated usually by collecting data with the normal pulse interval and then with a pulse interval several times the longest $\mathrm{Tl}$ (the spin-lattice relaxation time constant) so that the spin system is very nearly relaxed. Direct comparison of the resonance line areas then gives correction factors which can be applied to all subsequent data.

The signal has to be localized so that data are acquired only from the required tissue, and this can be achieved in several ways. The spatial sensitivity of circular surface coils as a function of flip angle and pulse repetition rate has been examined in detail $(23,31)$. A degree of localization can be obtained by judicious positioning of the coil adjacent to the muscle and by appropriate selection of the transmitted pulse length, interval, or sequence $(9,10,11)$. For ${ }^{31} \mathrm{P}-\mathrm{NMR}$ investigations, great benefit is obtained from the fact that most surface tissues do not contain detectable amounts of phosphorus metabolites, and simple muscle studies can be made by the use of a suitable size surface coil only. An alternative approach is to superimpose high-order profiled magnetic field gradients onto the main field (25), which are arranged so that only a defined volume of muscle experiences a homogeneous field. Nuclei in the field gradients resonate over a range of frequencies, and this broad signal can be removed by mathematical processing (26) to leave only the narrow resonance lines from the homogeneous region. In studies of muscle, signal localization has so far been achieved by the use of combinations of all these methods.

At the moment, techniques involving the application of field gradients are being developed to give the user more flexible localization and ability to define the shape, size, and position of the volume from which data is collected $(6,12,43)$. These methods are somewhat handicapped by the low concentrations and sensitivities of most potentially interesting nuclei. For muscles near to the skin surface, the user may still be better off in many applications using the simple surface coil technique.

If it is desired to localize the signal to a particular, deeper muscle, then more sophisticated techniques have to be applied in order to reduce signals from tissues closer to the coil. If ${ }^{13} \mathrm{C}$ or ${ }^{1} \mathrm{H}$ are studied, then some method of avoiding data contamination by signals from skin or subcutaneous fat has to be used. Studies using these two nuclei encounter other problems. Because of the magnetic struc- 


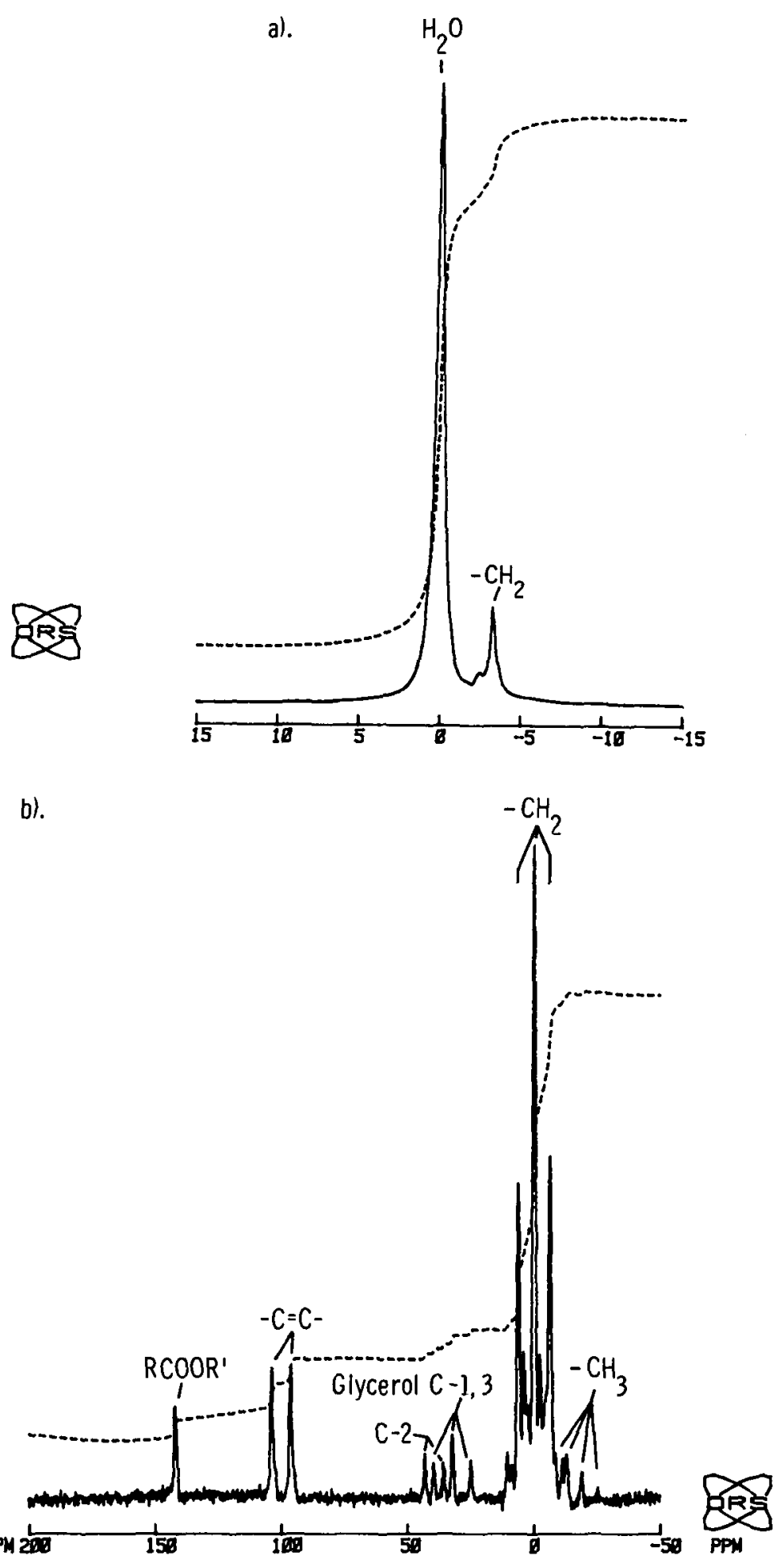

Figure 1. (a) ${ }^{1} \mathrm{H}$ spectrum obtained using a $2.5 \mathrm{~cm}$ diameter coil placed adjacent to the extensor digitorum muscle. $8 \times 75 \mu$ s pulses with a pulse interval of 1.256 s. The main peak is due to $\mathrm{H}_{2} \mathrm{O}$ protons; the other smaller resonances are due mainly to subcutaneous fat. (b) $A{ }^{13} \mathrm{C}$ spectrum collected with a $4 \mathrm{~cm}$ surface coil 
ture of organic molecules, ${ }^{13} \mathrm{C}$ spectra usually consist of resonance line multiplets which complicate spectral analysis. These multiplets can be condensed to single resonances by simultaneously applying decoupling $\mathrm{Rf}$ at the ${ }^{1} \mathrm{H}$ frequency. However, as this can cause tissue heating, the use of decoupling has to be approached very cautiously in living systems. ' $\mathrm{H}$ studies of tissue are handicapped by the presence of a very large $\mathrm{H}_{2} \mathrm{O}$ resonance which completely dominates the spectrum. Various pulse sequence techniques exist for the reduction of this signal $(33,40)$ although their usefulness with surface coils remains to be shown. The application of ${ }^{1} \mathrm{H}-\mathrm{NMR}$ to muscle shows great promise because of the greater sensitivity of the proton and the large number of potentially detectable metabolites including lactate, phosphocreatine (PCr), and creatine $(4,5)$.

\section{CLINICAL APPLICATIONS OF NMR SPECTROSCOPY TO MUSCLE DISEASE}

\section{Normal Muscle}

In order to use NMR spectroscopy to monitor physiological or pathological changes in muscle tissue, it is necessary to know the normal ranges for resting metabolite levels and intracellular $\mathrm{pH}$. Figures 1 and 2 show ${ }^{1} \mathrm{H},{ }^{13} \mathrm{C}$, and ${ }^{31} \mathrm{P}$ spectra obtained from normal, resting muscles. The ${ }^{1} \mathrm{H}$ spectrum (Figure la) consists mainly of a strong $\mathrm{H}_{2} \mathrm{O}$ resonance and a small peak due to $-\mathrm{CH}_{2}$ protons in triglycerides. Other resonances from metabolites of millimolar concentration such as creatine, phosphocreatine, and lactic acid are swamped by the strong $\mathrm{H}_{2} \mathrm{O}$ and $-\mathrm{CH}_{2}$ signals. If no precautions are taken to reduce surface tissue signals, the size of this $-\mathrm{CH}_{2}$ proton peak will depend largely on the subcutaneous fat thickness. In the coupled ${ }^{13} \mathrm{C}$ spectrum (Figure $\mathrm{lb}$ ), the predominant feature is the triplet, due to $-\mathrm{CH}_{2}$ carbon nuclei in triglyceride chains. Other prominent resonances are detected from $-\mathrm{CH}_{3}$, Glycerol, $-\mathrm{C}=\mathrm{C}-$, and $\mathrm{RCOOR}$ ' carbons. So far, the most illuminating results from muscle tissue have been obtained using ${ }^{31} \mathrm{P}$ NMR. The spectrum from normal, resting extensor digitorum (Figure 2) shows several prominent resonances from ATP (the $\gamma-, \alpha-$, and $\beta$-phosphorus nuclei), phosphocreatine (PCr), and inorganic phosphate (Pi). Signals from monoesters (mainly sugar-phosphates (SP) and phosphodiesters (PD) are also detected along with broad signals from immobile phosphorus in bone and phospholipids which in this spectrum have been removed mathematically to give a flat baseline. The $\mathrm{PCr}$ resonance usually has a very good signal-to-noise ratio and is commonly used as an internal reference for the determination of ${ }^{31} \mathrm{P}-\mathrm{NMR}$ chemical shifts. The $\mathrm{PCr}$ line profile is narrow and its chemical shift is not $\mathrm{pH}$ dependent, although there is some variation with the $\mathrm{Mg}^{2+}$ concentration. In most muscle studies the $\mathrm{PCr}$ resonance makes a good reference. However, in instances of $\mathrm{PCr}$ depletion,

placed on the belly of the calf. No proton decoupling was used. $512 \times 40 \mu \mathrm{s}$ pulses with an interval of $1.256 \mathrm{~s}$. The spectrum probably contains a significant amount of contamination from subcutaneous fat tissue. The prominent triplet at the right-hand end of the spectrum is due to the carbon nuclei in triglyceride chains. Spectrum [a] obtained with the assistance of N. Taylor. 


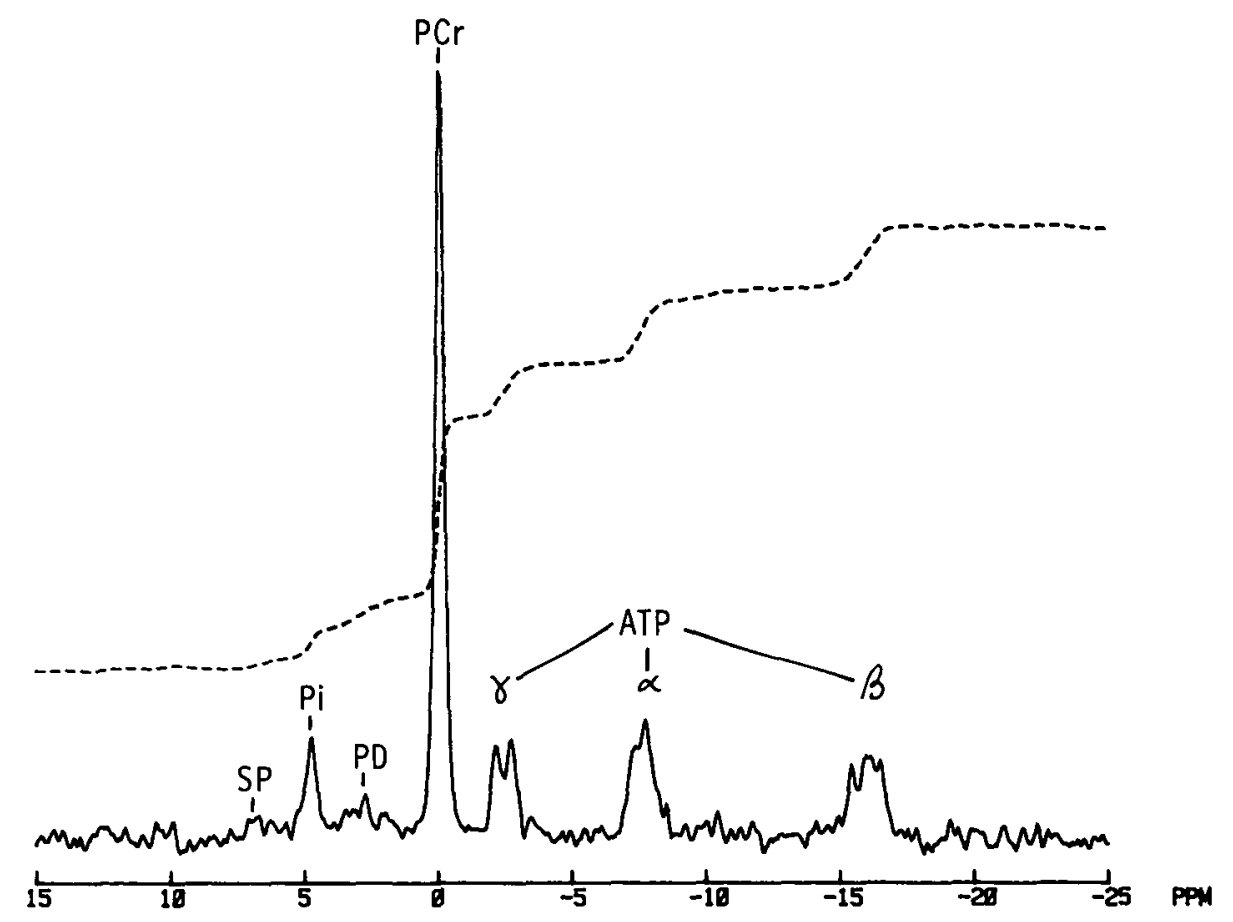

Figure 2. $\mathrm{A}{ }^{31} \mathrm{P}$ spectrum obtained from the extensor digitorum muscle using the same coil as in Figure 1a. $256 \times 13 \mu$ s pulses with an interval of $2.256 \mathrm{~s}$. Because of the very low concentrations of mobile ${ }^{31} \mathrm{P}$ metabolites in other adjacent tissues, metabolite levels determined from this spectrum are very close to those pertaining to the muscle tissue. Spectrum obtained with the assistance of $N$. Taylor.

it may be necessary to use other approaches, such as ${ }^{1} \mathrm{H}_{2} \mathrm{O}$ referencing (17). Mean values for the metabolite levels (relative to a total mobile and NMR-visible phosphate pool of 1) and $\mathrm{pH}$ of normal, resting, male calf muscle tissue are given in Table 1 (28).

Changes in normal metabolite levels and $\mathrm{pH}$ can be induced by ischemia (19) or exercise (46), and time resolution better than a minute can usually be obtained using the NMR technique. Figure 3 shows the response of muscle tissue to occlusion of arterial blood flow to the arm by a sphygmomanometer cuff for 35 minutes. Gradual depletion of $\mathrm{PCr}$ and increase of Pi occurs until the cuff is released. $\mathrm{PCr}+\mathrm{Pi}, \mathrm{ATP}$, and $\mathrm{pH}$ appear to stay constant throughout the study.

Metabolite changes can also be monitored during exercise, which for the subject can consist of squeezing an air bladder, moving a lever, or making isometric contractions, with a strain gauge to record the performance. Exercise can be continuous or prompted repeatedly by a signal synchronized to the Rf transmitted pulse, so that data are acquired only in the interval between contractions. Several resting spectra are obtained at first as a baseline followed by exercise spectra until sufficient changes have been observed. Exercise is then stopped and the recovery of metabolite levels and $\mathrm{pH}$ to the original resting levels is followed by collecting further spectra. Modern spectrometers with computer control have 
Table 1. Metabolite Ratios (Relative to Total Mobile Phosphate) for Normal Calf, Forearm, and Duchenne Dystrophy Calf.

\begin{tabular}{|c|c|c|c|c|c|c|}
\hline & \multicolumn{2}{|c|}{$\begin{array}{c}\text { Normal Calf } \\
\mathrm{n}=5\end{array}$} & \multicolumn{2}{|c|}{$\begin{array}{c}\text { Normal Forearm } \\
\mathbf{n}=24\end{array}$} & \multicolumn{2}{|c|}{$\begin{array}{c}\text { Duchenne } \\
\text { Dystrophy Calf } \\
\mathrm{n}=53\end{array}$} \\
\hline & (Mean) & (SD) & (Mean) & (SD) & (Mean) & (SD) \\
\hline$\beta$-АТP & 0.11 & 0.01 & 0.11 & 0.01 & 0.11 & 0.02 \\
\hline $\mathrm{PCr}$ & 0.47 & 0.02 & 0.49 & 0.03 & $0.39^{\mathrm{a}}$ & 0.04 \\
\hline $\mathrm{Pi}$ & 0.08 & 0.01 & 0.08 & 0.01 & $0.14^{\mathrm{a}}$ & 0.03 \\
\hline P-diester & 0.06 & 0.02 & 0.03 & 0.02 & 0.06 & 0.02 \\
\hline $\mathrm{PCr} / \mathrm{ATP}$ & 4.23 & 0.12 & 4.44 & 0.49 & $3.70^{\mathrm{a}}$ & 0.75 \\
\hline $\mathrm{PCr} / \mathrm{Pi}$ & 6.02 & 0.49 & 6.71 & 1.54 & $2.92^{\mathrm{a}}$ & 0.81 \\
\hline $\mathrm{PCr}+\mathrm{Pi}$ & 0.55 & 0.03 & 0.57 & 0.03 & 0.53 & 0.03 \\
\hline $\mathrm{pH}$ & 7.05 & 0.03 & 7.04 & 0.05 & 7.08 & 0.10 \\
\hline
\end{tabular}

a Significant difference $(p<.001)$ between normal and Duchenne calf.

the ability to run complete studies of this type with minimal operator intervention. Figure 4 shows the response of normal muscle tissue to a typical exercise test. $\mathrm{PCr}$ is rapidly consumed with accompanying accumulation of $\mathrm{Pi}$ and fall in $\mathrm{pH}$ due to lactate accumulation from glycolysis. Recovery of metabolites and $\mathrm{pH}$ to resting values is complete within about 5 minutes. Studies of normal exercizing muscle tissue in young and old populations have shown no significant differences, indicating that muscle changes in the elderly are not due to alterations in energy production (45).

\section{Duchenne Muscular Dystrophy}

A large amount of attention has been focused on the application of NMR spectroscopy to muscular dystrophy, and in particular to Duchenne dystrophy $(16,22,28,29,37)$. Table 1 shows the mean resting metabolite levels and $\mathrm{pH}$ as determined by ${ }^{31} \mathrm{P}-\mathrm{NMR}$ and indicates significant differences between values for $\mathrm{PCr}, \mathrm{Pi}, \mathrm{PCr} / \mathrm{Pi}$, and PCr/ATP when compared with age matched normals. The decrease in $\mathrm{PCr} / \mathrm{Pi}$ ratio to $50 \%$ and $\mathrm{PCr} / \mathrm{ATP}$ ratio to $90 \%$ of the normal resting values in the presence of a normal $\mathrm{H}^{+}$concentration could be related to changes in the creatine or ADP concentrations or the effectiveness of oxidative phosphorylation, perhaps in only some of the muscle fibers. A difference in resting $\mathrm{pH}$ has been reported (37), but this may be due to technique or the investigation of subjects with more advanced disease. Exercise studies have been performed on the forearm muscles of a seven-year-old boy with Duchenne dystrophy (28). Although exercise started from an initially reduced $\mathrm{PCr}$ and increased $\mathrm{Pi}$ level, during recovery $\mathrm{PCr}$ rose and $\mathrm{Pi}$ fell to the starting levels quite rapidly, indicating normal activity of the enzyme creatine kinase and normal mitochondrial function. This suggests that the altered resting metabolite levels do not prevent normal muscle activity and that fiber loss rather than reduction in "high energy" phosphates causes the muscle weakness as previously emphasized in needle biopsy studies (21). 


\section{P-METABOLITE AND PH CHANGES AT REST WITH ISCHAEMIA}

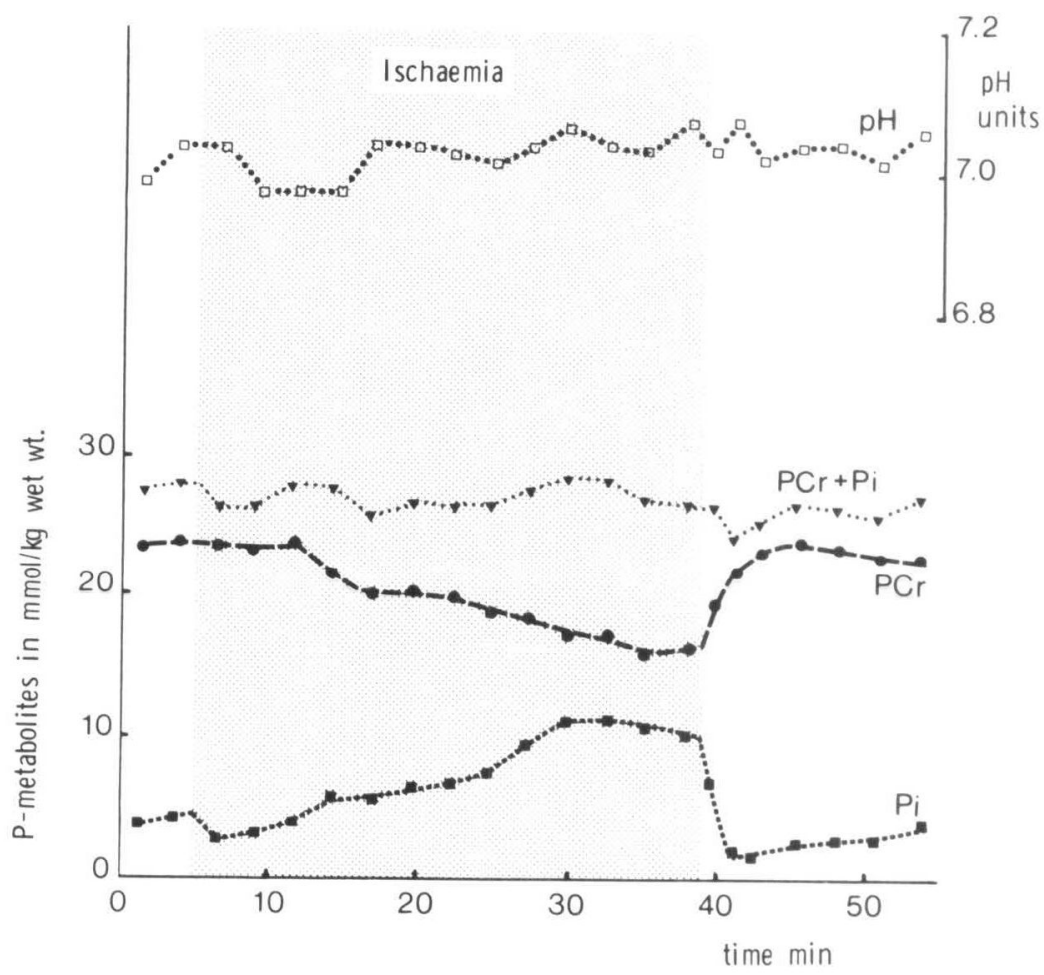

Figure 3. Changes in ${ }^{31} \mathrm{P}$ metabolites and $\mathrm{pH}$ in normal resting forearm muscle induced by occlusion of the arterial blood supply. Spectra were collected using a $6 \mathrm{~cm}$ surface coil placed over the forearm flexor muscle compartment. The pulse length was optimized for maximum signal: 32 pulses, pulse delay $2.256 \mathrm{~s}$.

\section{Other Myopathies}

Abnormal resting muscle spectra have been seen in only a few cases of myopathy apart from muscular dystrophy. The abnormalities reveal themselves as decreased $\mathrm{PCr} / \mathrm{Pi}$ ratios $(24,39)$, a reported increase in phosphodiester signal in hypothyroid myopathy (34) or alkaline $\mathrm{pH}$ (39). Exercise studies produce more interesting results.

Several cases of phosphofructokinase (PFK) deficiency have been examined $(18,22,30)$. Although resting metabolite levels and $\mathrm{pH}$ are normal, exercise leads to the detection by ${ }^{31} \mathrm{P}-\mathrm{NMR}$ of rapid accumulation of fructose-6-phosphate, a metabolite in the glycolytic pathway (see Figure 5). No significant change in $\mathrm{pH}$ has been reported in any study confirming the inability to produce lactic acid. On cessation of exercise, there is a slow recovery of $\mathrm{PCr}$ to the resting level. This could be due to the trapping of phosphate by fructose-6-phosphate generated by the enzyme block.

Another more common, but still rare, disorder is McArdle's syndrome (myophosphorylase deficiency), in which the patient is unable to utilize glycogen for 


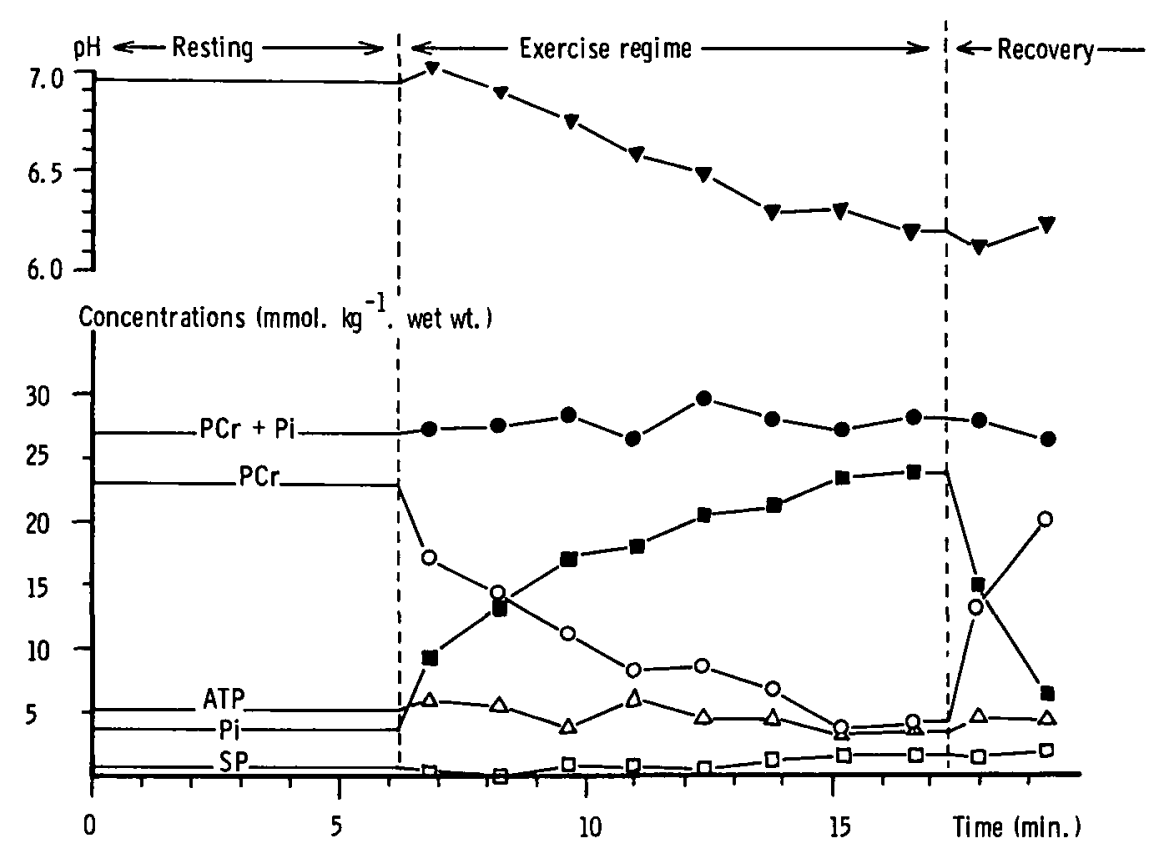

Figure 4. Response of normal muscle tissue to anaerobic contractions. During the exercise regime the arterial circulation was occluded by the application of a sphygmomanometer cuff controlled by compressed air. Exercise consisted of 32 $\times 1 \mathrm{sec} .20 \%$ maximum isometric voluntary contractions interleaved with data acquisition every $2.256 \mathrm{sec}$. Subject performance was monitored by the use of a strain gauge applied to the back of the hand. On alternate data collections the muscle was relaxed. At the end of the complete exercise sequence the cuff was let down and the metabolite levels allowed to recover. Conditions of data collection as for Figure 3. Metabolite concentrations were estimated using a total mobile phosphate concentration of $49.5 \mathrm{mmol} . \mathrm{kg}^{-1}$ wet wt. Source: Reference 20.

anaerobic glycolysis because of a deficiency of the enzyme phosphorylase. This has been studied in four patients using ${ }^{31} \mathrm{P}-\mathrm{NMR}(39,41)$. The resting metabolite levels were normal, and average resting $\mathrm{pH}$ was 7.05. During exercise there was a marked decrease in $\mathrm{PCr}$ and an increase in $\mathrm{Pi}$-but no intracellular acidosisin the patients with McArdle's syndrome, while in normal subjects $\mathrm{pH}$ decreased significantly due to lactic acid production. In fact, during exercise in the myophosphorylase-deficient muscle, pHs were consistently alkaline and could be estimated very well because of the high $\mathrm{Pi}$ and $\mathrm{PCr}$ signal-to-noise ratios.

A case of postviral myopathy following chickenpox has recently been investigated (3). The study revealed a very rapid intracellular acidosis on exercise and subsequently a slower than normal recovery of $\mathrm{PCr}$ to the resting level while $\mathrm{pH}$ recovered at the normal rate. The excess acidosis could have been caused by increased lactic acid production, reduced buffering capacity, or abnormal elimination of acid from the cytosol. Because of the normal $\mathrm{pH}$ late in the exercise protocol and the normal rate of $\mathrm{pH}$ recovery, it has been suggested that the ab- 


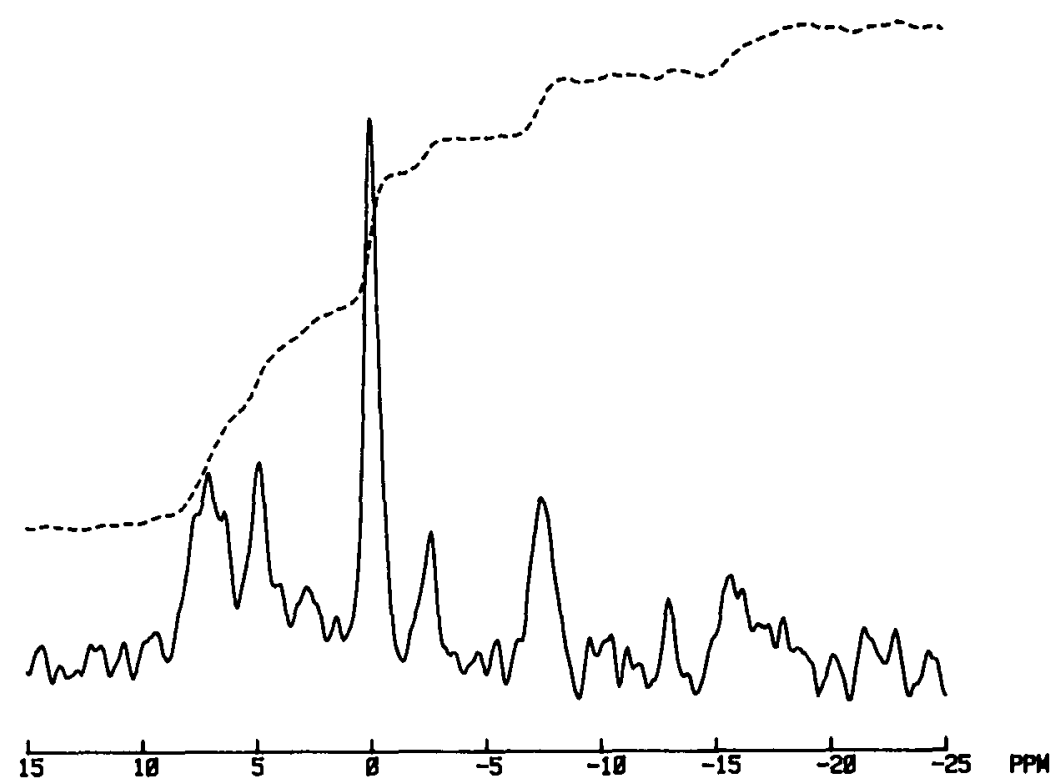

Figure 5. ${ }^{31} \mathrm{P}$ NMR spectrum of phosphofructokinase- (PFK) deficient forearm muscle during aerobic exercise. Note the greatly increased sugar phosphate peak at about 7 ppm due mainly to the accumulation of unmetabolized fructose-6phosphate. Data acquisition conditions as for Figure 3, but 64 pulses. The peak assignments are as for Figure 2.

normality may be due to a change in the relative contributions of glycolytic and oxidative processes. A low general mitochondrial activity in subjects with muscle pain has been described (35), and this therefore is not too surprising.

Hypothyroid myopathy has been investigated in two subjects. In one case, a raised phosphodiester level was reported (34), but in the other case (30), no significant abnormality at rest or during exercise and recovery was shown both before and 6 weeks after commencement of thyroxine, despite the subjects' regaining normal muscle function.

In a large number of patients with undiagnosed muscular pain and fatigue during or after exercise ${ }^{31} \mathrm{P}-\mathrm{NMR}$ has so far not shown any abnormality in spite of the possibility of energy supply defects. One group reports that out of 68 such cases, only $20 \%$ have shown a deviation from normal NMR results (39).

\section{Monitoring Chemotherapy}

Clinical NMR offers the possibility of monitoring the response of in situ tissue to therapeutic regimes. Of particular importance is the cytotoxic response of malignant tissue to chemotherapy; the noninvasive nature of NMR is ideally suited to this function. So far only one in situ malignant tumor (that of muscle, a rhabdomyosarcoma) has come under scrutiny (27). The ${ }^{31}$ P-NMR spectra from the tumor (see Figure 6) taken at the start and end of a six week course of chemotherapy were very different from a spectrum taken from a healthy volunteer which mainly represented interosseus muscle and was similar in appearance to Figure 2. 
a). Before.

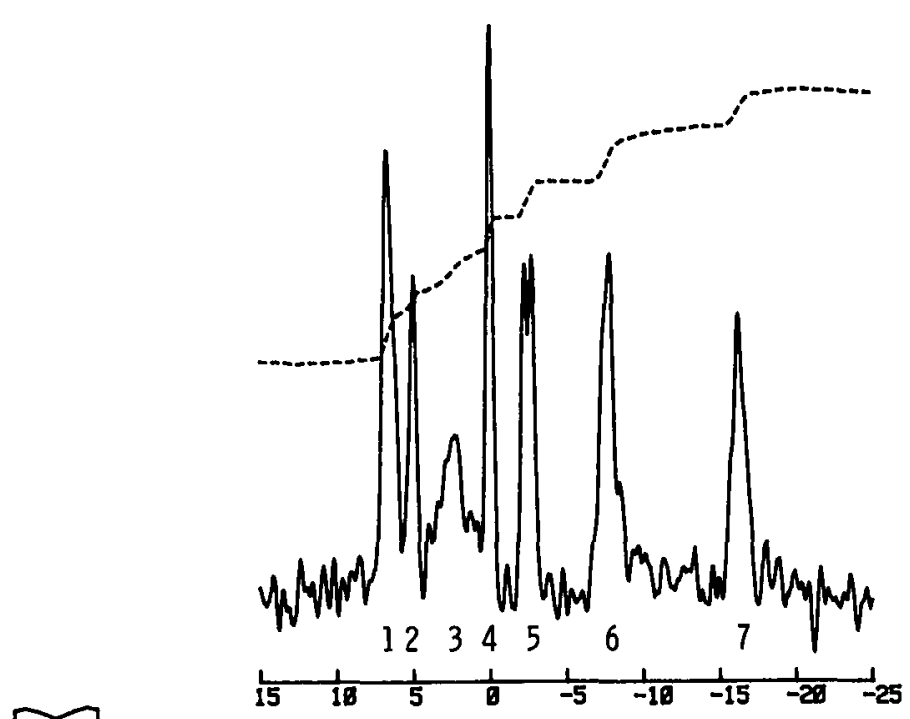

b). After.

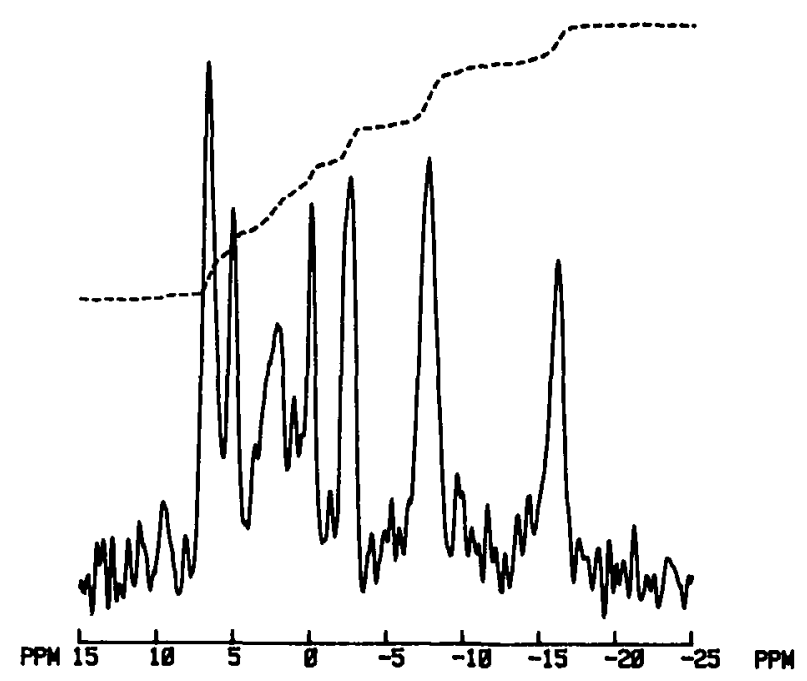

Figure 6. ${ }^{31}$ P-NMR spectra of a malignant tumor of muscle tissue (a rhabdomyosarcoma) taken before and after a course of chemotherapy. Spectra were collected using a $4 \mathrm{~cm}$ surface coil placed directly over the $5 \mathrm{~cm}$ long, $3.5 \mathrm{~cm}$ wide, $1 \mathrm{~cm}$ deep tumor on the dorsal surface of the hand. Each spectrum resulted from the sum of 512 free induction decays with a pulse interval of $2.5 \mathrm{~s}$ and a $24 \mu \mathrm{s}$ pulse length giving optimum signal from ${ }^{31} \mathrm{P}$ nuclei close to the coil. Legend: 1 phosphomonoester; 2-inorganic phosphate; 3-phosphodiester; 4-phosphocreatine; $5-\gamma$-ATP; $6-\alpha$-ATP; and $7-\beta$-ATP. It is possible that peaks 5 to 7 contain contributions from other di- and trinucleotides as well as NAD and NADH (peak 6). 
The most striking features were the presence of conspicuous peaks in the phosphomonoester and diester regions of the spectra and reduced $\mathrm{PCr} / \mathrm{Pi}$ and $\mathrm{PCr} /$ ATP ratios when compared with the normal subject's. The only differences between the tumor spectra before and after treatment were reductions in $\mathrm{PCr} / \mathrm{ATP}$ to $75 \%$ and $\mathrm{PCr} / \mathrm{Pi}$ to $70 \%$ of their initial values. In accord with the overall clinical situation and the absence of tumor resorption, this was taken to indicate deterioration. The ability to follow such changes indicates the potential for monitoring the effect of different cytotoxic chemotherapeutic regimes.

\section{FUTURE DEVELOPMENT OF CLINICAL NMR SPECTROSCOPY FOR MUSCLE STUDIES}

The more general application of NMR spectroscopy to muscle disease must be considered in the light of some of the other major clinical applications. ${ }^{31} \mathrm{P}-\mathrm{NMR}$ spectroscopy has already made a significant contribution to the study of neonatal cerebral metabolism $(14,32,48)$. Further advances in the investigation of the brain and other organs in adults and children will require the use of large-bore wholebody spectrometers which are recently available. Systems are also being developed to combine NMR imaging and spectroscopy (13). The considerable investment of financial and personnel resources in the management of a clinical NMR system will depend on its application to a broad medical horizon including both imaging and spectroscopy of many different organs. However, advantages arise from experience gained in studying other tissues, particularly in terms of the optimization of signal localization and sensitivity.

At present, the use of NMR in the study of muscle and other tissues is handicapped to some extent by the reliance on surface coil techniques. The development of methods by which the operator can know fairly precisely the location and shape of the tissue volume from which the NMR signal originates will be very beneficial. Some sensitivity problems are encountered when investigating deeper tissues. These may be avoided in the future if the potential of ${ }^{1} \mathrm{H}$ NMR is realized, especially if studies of the safety of NMR allow the introduction of higher magnet field strengths and hence better resolution and signal-to-noise ratios. The variety of metabolites that are available for study by ${ }^{1} \mathrm{H}$-NMR may make it unnecessary to use other nuclei in general, although there will always be special applications.

Several NMR systems offer the facilities of imaging (based on ${ }^{1} \mathrm{H}$ ) together with spectroscopy and will be of potential value in identifying more precisely the sensitive volume from which biochemical measurements are made. A further development which is in sight is the possibility of imaging with individual phosphorus-containing metabolites so as to give the topography of tissue biochemistry. The application to a myopathy would be to identify damaged and diseased volumes of muscle as well as the study of the homogeneity of energy exchanges in different parts of a muscle during its contraction. This has particular relevance to contracture development in patients with the glycolytic disorders already mentioned (McArdle's syndrome and phosphofructokinase deficiency), and such application may give diagnostic information in a wider range of causes of unexplained muscle pain. 


\section{REFERENCES}

1. Ackerman, J. J. H., Grove, T. H., Wong, G. G., Gadian, D. G., \& Radda, G. K. Mapping of metabolites in whole animals by ${ }^{31} \mathrm{P}$ NMR using surface coils. Nature, $1980,283,167-70$.

2. Alger, J. R., \& Shulman, R. G. Metabolic applications of high resolution ${ }^{13} \mathrm{C}$ nuclear magnetic resonance spectroscopy. British Medical Bulletin, 1984, 40, 160-64.

3. Arnold, D. L., Bore, P. J., Radda, G. K., Styles, P., \& Taylor, D. J. Excessive intracellular acidosis of skeletal muscle on exercise in a patient with post-viral exhaustion/fatigue syndrome. The Lancet, 1984, 1, 1367-69.

4. Arus, C., Barany, M., Westler, W. M., \& Markley, J. L. 'H NMR of intact tissues at 11.1T. Journal of Magnetic Resonance, 1984, 57, 519-25.

5. Arus, C., Barany, M., Westler, W. M., \& Markley, J. L. 'H NMR of intact muscle at 11T. FEBS Letter, 1984, 165, 231.

6. Aue, W. P., Muller, S., Cross, T. A. \& Seelig, J. Volume selective excitation: A novel approach to topical NMR. Journal of Magnetic Resonance, 1984, 56, 350-54.

7. Barany, M., Doyle, D. D., Graff, G., Westler, W. M., \& Markley, J. L. Natural abundance ${ }^{13} \mathrm{C}$ NMR spectra of human muscle, normal and diseased. Magnetic Resonance in Medicine, 1984, 1, 30-43.

8. Behar, K. L., den Hollander, J. A., Stromski, M. E., Ogino, T., Shulman, R. G., Petroff, O. A. C., \& Pritchard, J. W. High-resolution ' $\mathrm{H}$ nuclear magnetic resonance study of cerebral hypoxia in vivo. Proceedings of the National Academy of Sciences, $1983,80,4945-48$.

9. Bendall, M. R., \& Gordon, R. E. Depth and refocussing pulses designed for multipulse NMR with surface coils. Journal of Magnetic Resonance, 1983, 53, 365-85.

10. Bendall, M. R., \& Aue, W. P. Experimental verification of depth pulses applied with surface coils. Journal of Magnetic Resonance, 1983, 54, 149-52.

11. Bendall, M. R., \& Pegg, D. T. DEPT at depth: Polarization transfer and sample localization combined using surface coils. Journal of Magnetic Resonance, 1984, 57, 337-43.

12. Bottomley, P. A. Localized NMR spectroscopy by the sensitive point method. Journal of Magnetic Resonance, 1982, 50, 335-38.

13. Bottomley, P. A., Hart, H. R. Jr., Edelstein, W. A., Schenk, J. F., Smith, L. S., Leue, W. M., Mueller, O. M., \& Redington, R. W. Anatomy and metabolism of the normal human brain studied by magnetic resonance at 1.5 Tesla. Radiology, 1984, 150, 441-46.

14. Cady, E. B., Dawson, M. J., Hope, P. L., Tofts, P. S., Costello, A. M. de L., Delpy, D. T., Reynolds, E. O. R., \& Wilkie, D. R. Non-invasive investigation of cerebral metabolism in newborn infants by phosphorus nuclear magnetic resonance spectroscopy. The Lancet, 1983, 1, 1059-62.

15. Cady, E. B., Delpy, D. T., \& Tofts, P. S. Clinical ${ }^{31}$ P NMR spectroscopy. In R. A. Lerski, (ed.), Physical principles and clinical applications of NMR. Bristol: Adam Hilger, 1984.

16. Cady, E. B., Edwards, R. H. T., Griffiths, R. D., \& Wilkie, D. R. ${ }^{31}$ P nuclear magnetic resonance studies of leg muscle metabolites in Duchenne muscular dystrophy. Proc. Phys. Soc. April, 1984, 57.

17. Cady, E. B., \& Wilkie, D. R. Estimation of cerebral intracellular $\mathrm{pH}$ by ${ }^{31} \mathrm{P}$ NMR spectroscopy. In P. Rolfe, (ed.), Fetal and neonatal physiological measurements. London: Butterworths, in press.

18. Chance, B., Eleff, S., Bank, W., Leigh, Jr., J. R., \& Warnell, R. ${ }^{31}$ P NMR studies of control of mitochondrial function in phosphofructokinase-deficient human skeletal muscle. Proceedings of the National Academy of Sciences, 1982, 79, 7714-18. 
19. Cresshull, I. D., Dawson, M. J., Edwards, R. H. T., Gadian, D. G., Gordon, R. E., Radda, G. K., Shaw, D., \& Wilkie, D. R. Human muscle analyzed by ${ }^{31} \mathrm{P}$ nuclear magnetic resonance in intact subjects. Journal of Physiology, 1981, 317, 18.

20. Dawson, M. J. Quantitative analysis of metabolite levels in normal human subjects by ${ }^{31} \mathrm{P}$ topical magnetic resonance. Bioscience Reports, 1982, 2, 727-33.

21. Edwards, R. H. T. Energy metabolism in normal and dystrophic human muscle. In L. P. Rowland, (ed.), Pathogenesis of human muscular dystrophies. Amsterdam: Excerpta Medica, 1977, 416-28.

22. Edwards, R. H. T., Dawson, M. J., Wilkie, D. R., Gordon, R. E., \& Shaw, D. Clinical use of nuclear magnetic resonance in the investigation of myopathy. The Lancet, 1982, $1,725-31$.

23. Evelhoch, J. L., Crowley, M. G., \& Ackerman, J. J. H. Signal-to-noise optimization and observed volume localization with circular surface coils. Journal of Magnetic Resonance, 1984, 56, 110-24.

24. Gadian, D. G., Radda, G. K., Ross, B., Hockaday, J., Bore, P., Taylor, D. J., \& Styles, $\mathrm{P}$. Examination of a myopathy by phosphorus nuclear magnetic resonance. The Lancet, 1981, 2, 774-75.

25. Gordon, R. E., Hanley, P. E., Shaw, D., Gadian, D. G., Radda, G. K., Styles, P., Bore, P. J., \& Chan, L. Localization of metabolites in animals using ${ }^{31} \mathrm{P}$ topical magnetic resonance. Nature, 1980, 287, 736-38.

26. Gordon, R. E., Hanley, P. E., \& Shaw, D. Topical magnetic resonance. Progress in NMR Spectroscopy, 1982, 15, 1-47.

27. Griffiths, J. R., Cady, E. B., Edwards, R. H. T., McCready, V. R., Wilkie, D. R., \& Wiltshaw, E. ${ }^{31} \mathrm{P}$ NMR studies of a human tumor in situ. The Lancet, 1983, 1, 143536.

28. Griffiths, R. D., Cady, E. B., Edwards, R. H. T., \& Wilkie, D. R. Muscle energy metabolism in Duchenne dystrophy studied by ${ }^{31} \mathrm{P}$ NMR: Controlled trials show no effect of allopurinol or ribose. Muscle and Nerve. Submitted for publication.

29. Griffiths, R. D., Cady, E. B., Edwards, R. H. T., \& Wilkie, D. R. ${ }^{31}$ phosphorus nuclear magnetic resonance used in a double blind trial of allopurinol in Duchenne muscular dystrophy. Clinical Science, 1984, 66, 16.

30. Griffiths, R. D., Edwards, R. H. T., \& Cady, E. B. 31-P NMR studies of human myopathy. Proceedings of INCONSIM (30th May, 1984) Lisbon, Portugal. Portuguese Society of Radiology and Nuclear Medicine.

31. Haase, A., Hanicke, W., \& Frahm, J. The influence of experimental parameters in surface coil NMR. Journal of Magnetic Resonance, 1984, 56, 401-12.

32. Hope, P. L., Costello, A. M. de L., Cady, E. B., Delpy, D. T., Tofts, P. S., Chu, A., Hamilton, P. A., Reynolds, E. O. R., \& Wilkie, D. R. Cerebral energy metabolism studied wth phosphorus NMR spectroscopy in normal and birth-asphyxiated infants. The Lancet, 1984, 2, 366-70.

33. Hore, P. J. Solvent suppression in Fourier transform nuclear magnetic resonance. Journal of Magnetic Resonance, 1983, 55, 283-300.

34. Iles, R. A., Stevens, A. N., \& Griffiths, J. R. NMR studies of metabolites in living tissue. Progress in NMR Spectroscopy, 1982, 15, 49-200.

35. Mills, K. R., \& Edwards, R. H. T. Investigative strategies for muscle pain. Journal of Neurological Sciences, 1983, 58, 73-88.

36. Moon, R. M., \& Richards, J. H. pH by ${ }^{31} \mathrm{P}$ magnetic resonance. Journal of Biological Chemistry, 1973, 248, 7276-78.

37. Newman, R. J., Bore, P. J., Chan, L., Gadian, D. G., Styles, P., Taylor, D. J., \& Radda, G. K. Nuclear magnetic resonance studies of forearm muscle in Duchenne dystrophy. British Medical Journal, 1982, 284, 1072-74.

38. Radda, G. K., \& Steiner, R. E., eds. Nuclear magnetic resonance and its clinical applications. British Medical Bulletin, 1984, 40. 
39. Radda, G. K., Bore, P. J., \& Rajagopalan, B. Clinical aspects of ${ }^{31}$ P NMR spectroscopy. British Medical Bulletin, 1984, 40, 155-59.

40. Redfield, A. G., Kunz, S. D., \& Ralph, E. K. Dynamic range in Fourier transform proton magnetic resonance. Journal of Magnetic Resonance, 1975, 19, 114-17.

41. Ross, B. D., Radda, G. K., Gadian, D. G., Rocker, G., Esiri, M., \& Falconer-Smith, J. Examination of a case of suspected McArdle's syndrome by ${ }^{31} \mathrm{P}$ NMR. New England Journal of Medicine, 1981, 304, 1338-42.

42. Saunders, R. D., \& Smith, H. Safety aspects of NMR clinical imaging. British Medical Bulletin, 1984, 40, 148-54.

43. Scott, K. N., Brooker, H. R., Fitzsimmons, J. R., Bennett, H. F., \& Micks, R. C. Spatial localization of ${ }^{31} \mathrm{P}$ nuclear magnetic resonance signal by the sensitive point method. Journal of Magnetic Resonance, 1982, 50, 339-44.

44. Slichter, C. P. Principles of magnetic resonance. 2nd Edition. Springer Verlag, 1978.

45. Taylor, D. J., Crowe, M., Bore, P. J., Styles, P., Arnold, D. L., \& Radda, G. K. Examination of the energetics of aging skeletal muscle using nuclear magnetic resonance. Gerontology, 1984, 30, 2-7.

46. Taylor, D. J., Bore, P. J., Styles, P., Gadian, D. G., \& Radda, G. K. Bioenergetics of intact human muscle. A ${ }^{31} \mathrm{P}$ nuclear magnetic resonance study. $\mathrm{Mol}$. Biol. Med. $1983,1,77-94$.

47. Wilkie, D. R., Dawson, M. J., Edwards, R. H. T., Gadian, D. G., \& Shaw, D. ${ }^{31}$ P NMR studies of resting muscle in normal human subjects. In G. H. Pollack \& H. Sugi (eds.), Contractile mechanisms in muscle. Vol. 2: Mechanics, energetics and molecular models. New York: Plenum Press, 1984, 333-47.

48. Younkin, D. P., Delivoria-Papadopoulos, M., Leonard, J. C., Subramanian, V. H., Eleff, S., Leigh, Jr., J. S., \& Chance, B. Unique aspects of human cerebral metabolism evaluated with 31-P NMR spectroscopy. Annals of Neurology, in press. 